
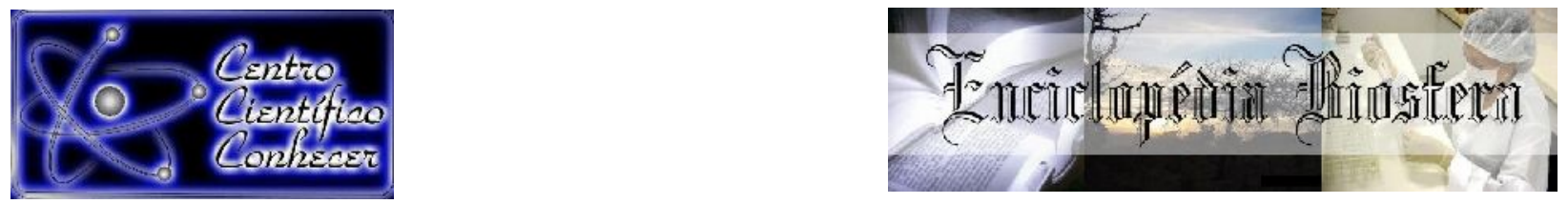

\title{
QUALIFICATION PROCEDURE OF A CORONA TYPE AEROSOL NEUTRALIZER
}

\author{
Bruno de Araújo Lima1, Paolo Maria Tronville², Mônica Lopes Aguiar ${ }^{3}$ \\ ${ }^{1}$ Mestre em Engenharia Química/Universidade Federal de São Carlos (UFSCar). São \\ Carlos/SP, Brasil.E-mail: bruno.ligno@gmail.com \\ ${ }^{2}$ Professor Associado Confirmado do Departamento de Energia do Politecnico di Torino \\ (Polito). Torino/TO, Italia. \\ ${ }^{3}$ Professora Titular do Departamento de Engenharia Química da Universidade Federal de \\ São Carlos (UFSCar). São Carlos/SP, Brasil.
}

Recebido em: 04/10/2019 - Aprovado em: 30/11/2019 - Publicado em: 15/12/2019 DOI: 10.18677/EnciBio_2019B47

\begin{abstract}
Air filtration helps prevent damage to the environment, damage to human health and damage to equipment in various industrial processes. Due to the relevance of this operation and its advantages over other gas-solid separation equipment, it is essential to obtain more reliable experimental data for both the industrial and scientific fields, because accurate reading of the equipment guarantees its best performance and reliability to process validation. Therefore, the objective of this paper was to qualify an important part of the air filtration process and to demonstrate its great importance for obtaining reliable data. The qualification consists of tests to ensure greater equipment efficiency and representativeness of the data obtained. The equipment in question is a Corona type aerosol neutralizer. The tests were carried out at the Politecnico di Torino Department of Energy in Italy and showed how the operation of this equipment can influence the reading of the sampled particles and, consequently, the filtration efficiency results. So, every effort has been made to ensure the correct functioning of the aerosol neutralizer and thus to obtain data consistent with reality.
\end{abstract}

KEYWORDS: Aerosol neutralization, Test rig qualification, Corona discharger.

\section{PROCEDIMENTO DE QUALIFICAÇÃO DE UM NEUTRALIZADOR DE AEROSSOL DO TIPO CORONA}

\section{RESUMO}

O processo de filtração do ar ajuda a evitar danos ao meio ambiente, danos à saúde dos seres vivos e danos aos equipamentos em processos industriais. Devido a importância desse processo e suas vantagens é imprescindível uma maior confiabilidade dos dados obtidos experimentalmente no campo industrial e científico, pois assim é possível a melhor leitura dos acontecimentos no processo e proporcionar seu desenvolvimento. O objetivo deste trabalho é mostrar como se realiza a qualificação de uma parte importante dentro do processo de filtração de ar e porque é importante. A qualificação consiste em testes para garantir maior eficiência do equipamento e representatividade dos dados obtidos. $O$ equipamento em questão é um neutralizador de aerossol do tipo Corona. Os testes foram 
realizados no Departamento de Energia do Politecnico di Torino na Itália e mostraram como a operação deste equipamento pode influenciar bastante a leitura das partículas amostradas e, consequentemente, os resultados de eficiência de filtração obtidos. Sendo assim, todo esforço feito para garantir que o neutralizador de aerossol funcione corretamente é muito benéfico, uma vez que os dados obtidos são condizentes com a realidade.

PALAVRAS-CHAVE: Corona Discharger, Neutralização de aerossol, Qualificação de equipamento.

\section{INTRODUCTION}

Air pollution caused in recent decades by increasing urbanization and industrial and technological advances has caused suffering in many metropolitan areas worldwide (TAGHVAEE et al., 2019). According to the World Health Organization, more than $90 \%$ of the world's population is exposed to air pollution concentrations that exceed their limits (WHO, 2018). In addition, this pollution was responsible for about 7 million premature deaths in 2012 worldwide (WHO, 2014). Airborne particulate matter, especially ultrafine, is related to various types of disease, such as neurological, cardiovascular, respiratory and pulmonary diseases (GAUDERMAN et al., 2015; WAl et al., 2015; ZHENG et al., 2018; STACEY, 2019).

In addition to the remarkable impact that airborne particulate matter has on human health, there is also the impact on the environment and climate change (LI et al., 2016). These factors, together with the demands of environmental agencies that regulate emissions and the constant need for cost reduction and optimization of the efficiency of industrial processes, make it necessary to develop air filtration techniques and technologies (BENNET, 2016; BULEJKO et al., 2019).

The quantitative characterization of particle size distribution is very important for a proper understanding of aerosols and for the development of control and prevention techniques (NGUYEN et al., 2014). The most used ultrafine particle size distribution measurement system is the Scanning Mobility Particle Sizer (SARANGI et al., 2015; TAN et al., 2016; MARIAN et al., 2017). SMPS is composed of a Differential Mobility Analyzer, which classifies particles according to electrical mobility, and a Condensation Particle Counter (SARANGI et al., 2017). In the particle classification step in the DMA it is necessary that the electrical charge distribution of the particles be known (WANG et al., 2014) and the way to do this is using aerosol neutralizers.

The main purpose of the neutralizers device is to provide equilibrium state of the distribution charges for an aerosol with unknown distribution (Jl et al., 2004; STOMMEL; RIEBEL, 2005). When the aerosol particles flow through the neutralizer, they can reach the equilibrium state of charge, and their initial charge state is eliminated. Charges balancing is described by the Boltzmann distribution. The most widely used method for charge conditioning of an aerosol or particles is diffusion charging in an atmosphere of bipolar ions using neutralization devices (KALLINGER et al., 2012). The most commonly used neutralizers are weak radioactive sources, such as Kr-85, Am-241 or Po-210, or Corona Discharger (KALLINGER et al., 2012; ALONSO; ALGUACIL, 2008). The efficiency of the neutralizer depends on the intensity of the radioactive source, ion generation rate and structure and format of the neutralizer (JI et al., 2004). Commercial neutralizers are constructed to provide sufficient residence time for the aerosol to achieve equilibrium of its charges. 
Radioactive sources can generate a maximum of $10^{7}$ ions $/ \mathrm{cm}^{3}$, which is not enough to establish the equilibrium state of the aerosol loads with concentrations greater than $10^{6}$ particles $/ \mathrm{cm}^{3}$ (ADACHI et al., 1989). Negative points of the use of this type of source are the legal restrictions for purchase and handling and also limited concentrations (ADACHI et al., 1993).

The Corona Discharger aerosol neutralizer generates ions by applying electrical tensions on the order of $\mathrm{kV}$ in very thin wires in a confined space (KALLINGER et al., 2012). A Corona discharger can be unipolar, either negative or positive, or bipolar and can operate with direct current or alternate current. The ionization of the aerosol occurs when it travels between confined space where there is a very high electric field (KALLINGER et al., 2012). The distribution of the aerosol charges depends on the $\mathrm{I}^{+} / \mathrm{I}^{-}$ion current rate. When this rate is equal to 1 , the neutralizer can effectively provide the Boltzmann equilibrium to either uncharged particles, highly unipolarly charged particles or highly biporlally charged particles, both in micrometric and nanometric scale with concentrations in the range of $6 \times 10^{3}$ to $2 \times 10^{6}$ particles $/ \mathrm{cm}^{3}$ (ADACHI et al., 1993).

Four different neutralizers devices were tested. A radioactive neutralizer of Am-241, a Corona Discharger of alternating current and two soft X-ray (SXR). This test were carried out using $0.01 \%$ Di-Ethyl-Hexyl-Sebacate (DEHS) solution in 2Propanol to generate the aerosol with different flowrates. The nanoparticle charging results showed that the electrical charge conditioning performed with the Corona discharger and both the SXR created ions very similar to the results obtained with radioactivity (KALLINGER et al., 2012). Also, the geometry of neutralizers devices does not directly affect its effect, however, residence time affects, mainly liquid particles due to evaporation.

Therefore, the present study aims to qualify a corona discharge aerosol neutralizer, since one way to ensure greater reliability is the qualification of the test rig used for the filtration tests (SACHINIDOU et al.,2017), and show how this part of the process is very important for aerosol filtration.

\section{MATERIALS AND METHODS}

The test equipment that was used to determine filter efficiency belongs to the Department of Energy of the Politecnico di Torino and is illustrated in Figure 1.

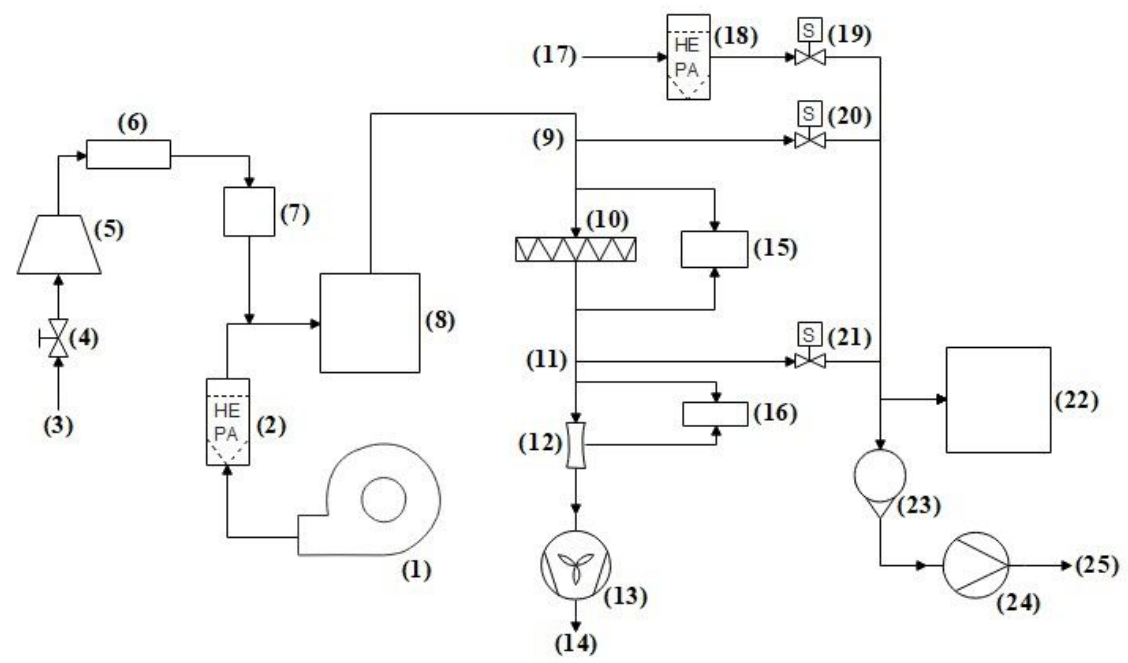

FIGURE 1. Polito's test rig schematics. (Source: Personal Archive). 
Air from the Air supply fan (1) passes through HEPA filter (2) and proceeds clean towards Plenum (8). The aerosol is generated from clean Compressed air (3) and Aerosol generator (5), controlled by a Manual valve (4). This aerosol proceeds to Diffusion dryer (6) and Corona type neutralizer (7), where it will have reduced moisture and its electrical charges arranged for the best reading of Particle Counter (22). The aerosol and clean air mix in the (8) Plenum and proceed to the filtration area. The aerosol passes through the filter media (10) through the diaphragm (12) and is expelled into the environment (14) by the exhaust fan (13). The pressure drop of the filter medium is measured by a Manometer (15) and the flow rate inside the duct is also measured by another Manometer (16) according to the pressure drop in the Diaphragm. The point where the aerosol issampled is determined by the solenoid valves. When Solenoid valve (20) for upstream sampling is triggered, sampling is performed at Upstream sampling point (9). When Solenoid valve (21) for downstream sampling is triggered, sampling is performed at Downstream sampling point (11). When the Solenoid valve (19) for cleaning is activated, ambient air sampling (17) is passed through a HEPA filter (18). A portion of the sample is sent to Particle Counter (22) and the remainder is expelled from the system (25). The sampling rate is controlled by one Rotameter (23) and one Pump (24).

\section{Corona discharger neutralizer effectiveness check}

Several methods exist to verify the effectiveness of a neutralizer. The method presented in this study is valid for the corona type neutralizer, also known as "Corona Discharger".

The neutralizer used in the lab is the TSI Aerosol Neutralizer model 8113. A sufficiently high electric field is applied to a metal wire of very small diameter, causing the free electrons present in the vicinity to be violently accelerated. When they reach the gas-surrounded molecules, the impact is strong enough to "steal" other electrons, creating new free electrons and positive ions.

To check properly the effectiveness of a corona type neutralizer is necessary to determine the correct operation of the instrument first and then find the setting that best represents the neutralization efficiency results. To do this it is necessary to test the filter media efficiency varying the neutralizer configuration. The condition of lower efficiency of the filter media will correspond to the state of higher neutralizer efficiency. In fact, the neutralizer is equipped with three screws, which allow to adjust the excitation frequency and the electrode voltage. The Figure 2 shows the screws adjustment positions.

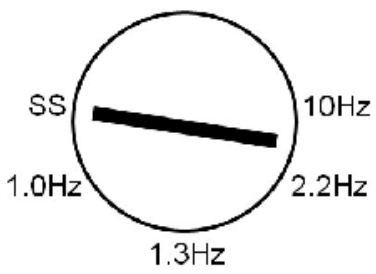

PULSE RATE
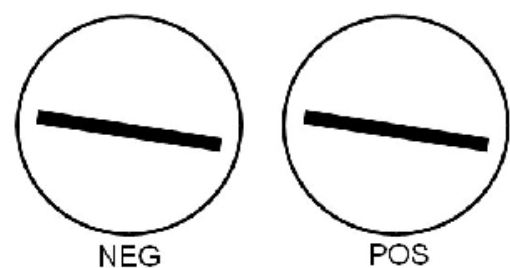

LEVEL

FIGURE 2. Screws adjustments for the Aerosol Neutralizer TSI 8113 (Source: Personal Archive). 
The pulse rate screw adjusts the current pulse. This screw can be positioned using a small screwdriver in five preset positions corresponding to five different frequencies: SS (0 Hz or DC), $1.0 \mathrm{~Hz}, 1.3 \mathrm{~Hz}, 2.2 \mathrm{~Hz}$ and $10 \mathrm{~Hz}$. Similarly, the positive and negative voltage level can be regulated with two level screws. These two screws, unlike the pulse rate bolt, have no pre-defined positions, they are free to rotate clockwise in a range of $3.5 \mathrm{kV}$ to $8 \mathrm{kV}$.

\section{- Electret filter media check}

This method relies on the use of an electret filter media. The use of a filter has most of its effectiveness due to the electrostatic filtration mechanisms, so it is important that the effect can be easily measured.

Electret filter media available for this test were two: "Nanoweb FA6900NW" and "Technostat", both produced by "Hollingsworth \& Vose". Before proceeding with the qualification of the neutralizer, a test should be done to confirm the electrostatic behavior of filter media.

The most common way to confirm that the electrostatic forces are the primary mechanism of filtration is to measure the filter efficiency before and after discharging the filter. The filtration due to the electrostatic forces could be substantial when the filter media is charged and the surface potential of the filter could be reduced down to zero by exposing it to an Isopropyl Alcohol (IPA) vapor (OHMI et al.,1994; XIAO et al.,2014). To discharge the filters the process used is an IPA bath for two minutes and twenty-four hours of natural drying. Tests with filter media charged and discharged were made with filtration superficial velocity of $5 \mathrm{~cm} / \mathrm{s}$ using TSI NanoScan as a particle counter and a $0,1 \%$ DEHS solution in IPA to generate the aerosol.

\section{- Excitement and balancing}

The qualification of the neutralizer process can be summed up with these five steps:

a) Installation of the Neutralizer.

b) Measurement of electret filter efficiency with the neutralizer off.

c) Measurement of electret filter efficiency with the neutralizer on.

d) Setting the frequency and voltage to minimize the measured efficiency of the electret filter.

e) Measurement of electret filter efficiency with the neutralizer off.

The efficiency of the electret filter medium is measured twice without the neutralizer: first before performing the tests with the neutralizer and the second time after the adjustment. This should be done to check the influence of neutralization on the electret material, because if the two efficiencies recorded without neutralizer are different, this means that the test is affecting the charge on the filter media and the test should be repeated with the concentration aerosol reduced or with a reduced duration.

As explained above, the voltage of the two poles can be varied by changing the screw position, however, the neutralizer does not have a precise position to show the selected voltage. As the screw is free, the only marked positions are the minimum and maximum voltages. As regards the frequency, three of five possible positions 
were chosen: DC, $1.3 \mathrm{~Hz}$ and $10 \mathrm{~Hz}$. For each frequency it was tested two voltage combinations, the minimum and maximum voltage choosing equal values for both

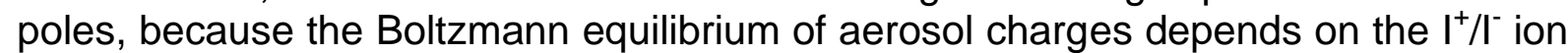
current rate to be as close as possible to 1 (ADACHI et al., 1993). The counter used was TSI NanoScan with 6 sampling cycles of 60 seconds per step and filtration superficial velocity of $5 \mathrm{~cm} / \mathrm{s}$.

\section{- Varying the concentration}

At the end of the balance and excitement test, the effectiveness of the neutralizer was also tested at lower concentrations. The particles concentration is controlled by adjusting the flow of pressurized air entering the atomizer. For these tests, the neutralizer was defined according to the results of the previous section, namely, DC $-3.5 \mathrm{kV}+3,5 \mathrm{kV}$. The same procedure presented in the previous section was used. Also, the tests are performed without neutralizing before and after the test, to analyze if it affects the filtration performance of the material.

\section{RESULTS AND DISCUSSION}

The efficiency measured after the discharge process with the IPA bath is decreased by several percentage points when compared to results for each filter media charged. Therefore, there is a strong electrostatic nature of the filtration mechanism for the filters charged (XIAO et al., 2014; SACHINIDOU et al., 2017). This result is in the Figure $3 \mathrm{a}$ and 3b, for the filter medium "FA6900NW" and the filter medium "Technostat", respectively.

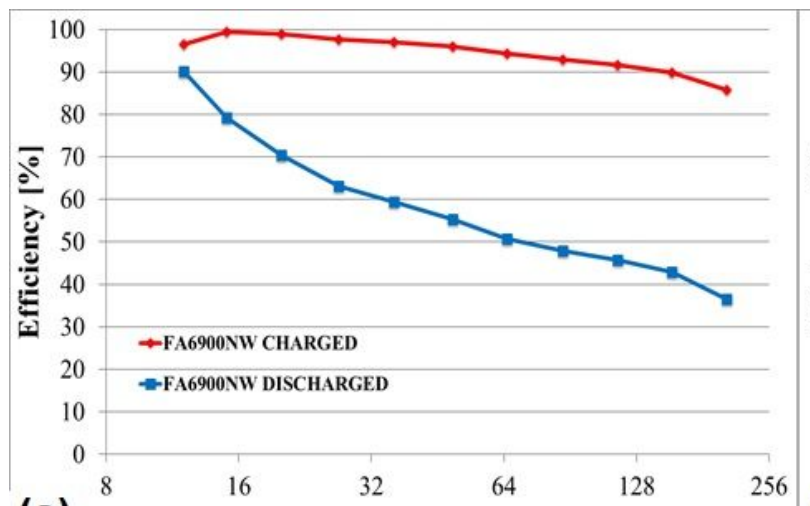

(a) ${ }^{8} \quad$ Electrical mobility particle size $[\mathrm{nm}]$

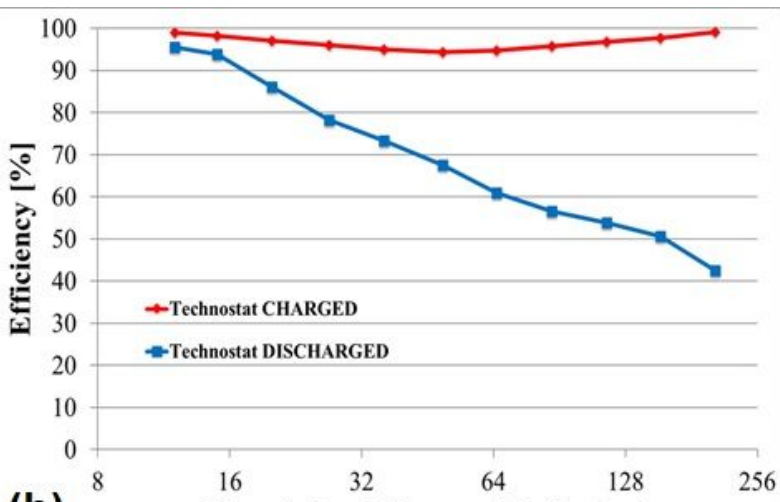

(b) Electrical mobility particle size $[\mathrm{nm}]$

FIGURE 3. Comparison of (a) FA6900NW and (b) Technostat efficiency before and after discharge.

Figures 4 and 5 show the curves of neutralization raised in the qualification process described in excitement and balancing section. 


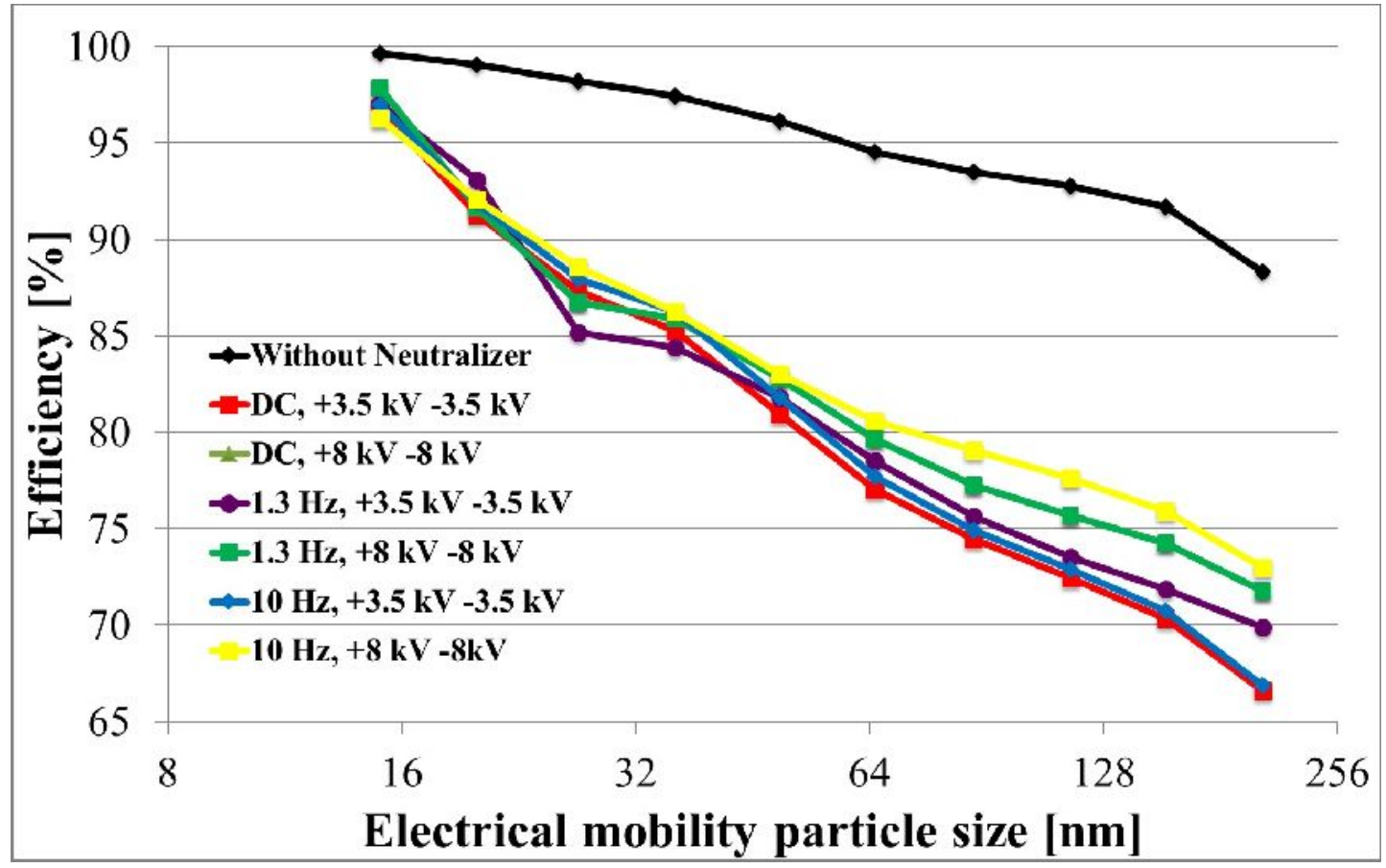

FIGURE 4. FA6900NW filter media efficiency tests with different neutralizer configurations.

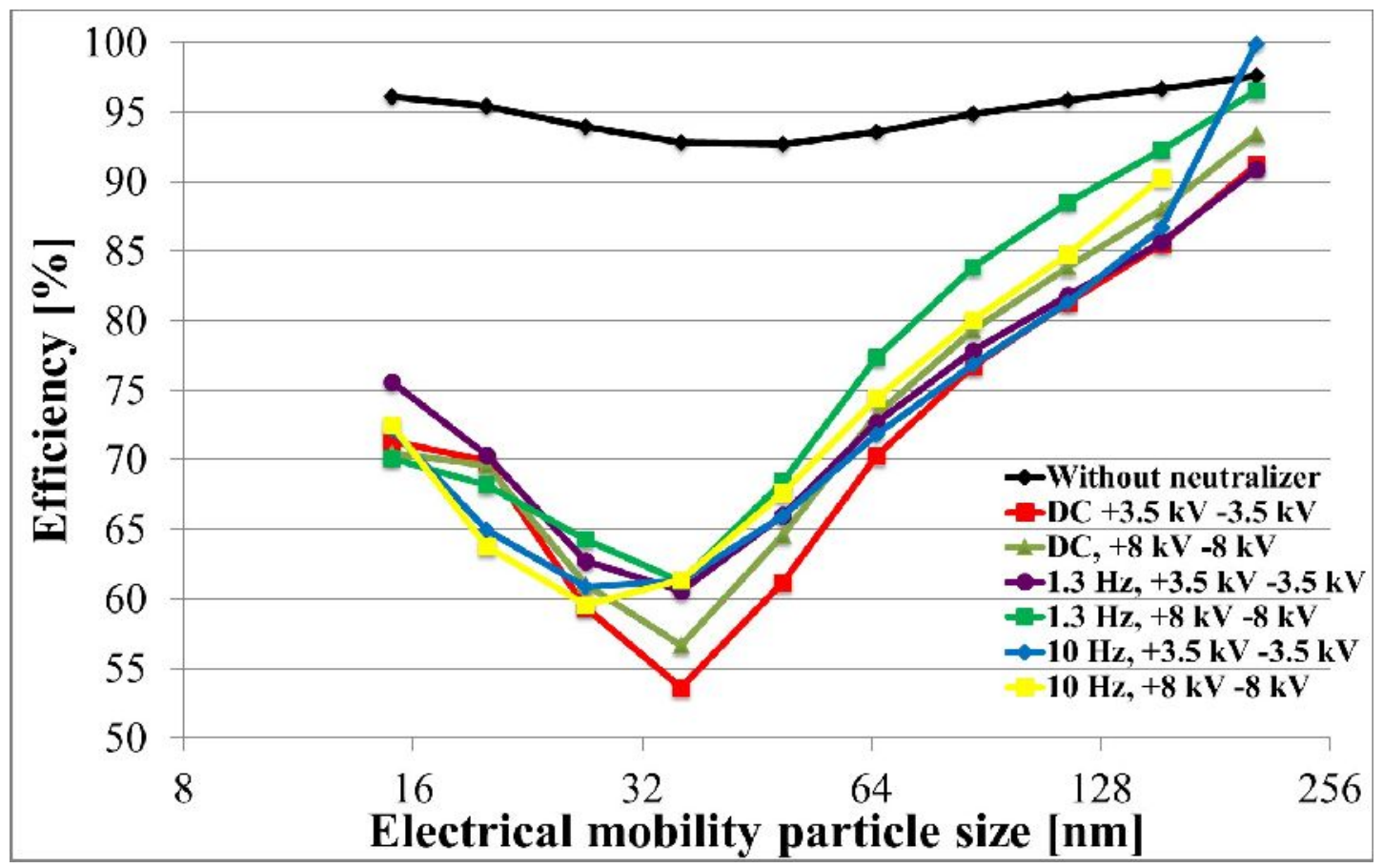

FIGURE 5. Technostat filter media efficiency tests with different neutralizer configurations.

From tests performed it can be seen as neutralizer has a considerable impact on filtration efficiency, since particle size distribution and charges can affect the efficiency tests accuracy (SACHINIDOU et al., 2016). However, it was not possible to identify a particular combination of frequency and voltage so that the efficiency is 
proven to be significantly lower than in all other cases. Furthermore, the performance of the neutralizer is more efficient according to the selected type of filter medium, since for the FA6900NW filter medium the main collection mechanism in the analyzed particle size range was diffusion and for the Technostat filter media diffusion occurred predominantly for particles smaller than $36 \mathrm{~nm}$ and above this particle size the main collection mechanism was the impaction (HINDS, 1999). This behavior depends not only on filtration parameters such as surface velocity, temperature, etc., but also on filter material parameters such as fiber thickness and diameter and particle parameters such as density and charges (WANG; TRONVILLE, 2014). The efficiency curves in Figures 4 and 5 shows the different behaviors. As there was not a configuration that achieved a better performance, it was decided to use for further measurements to define that, on average, performed well in both tests: $\mathrm{DC}-3.5 \mathrm{kV}+3.5 \mathrm{kV}$.

Figures 6 and 7 shown the results obtained for the filter media FA6900NW and Technostat, respectively.

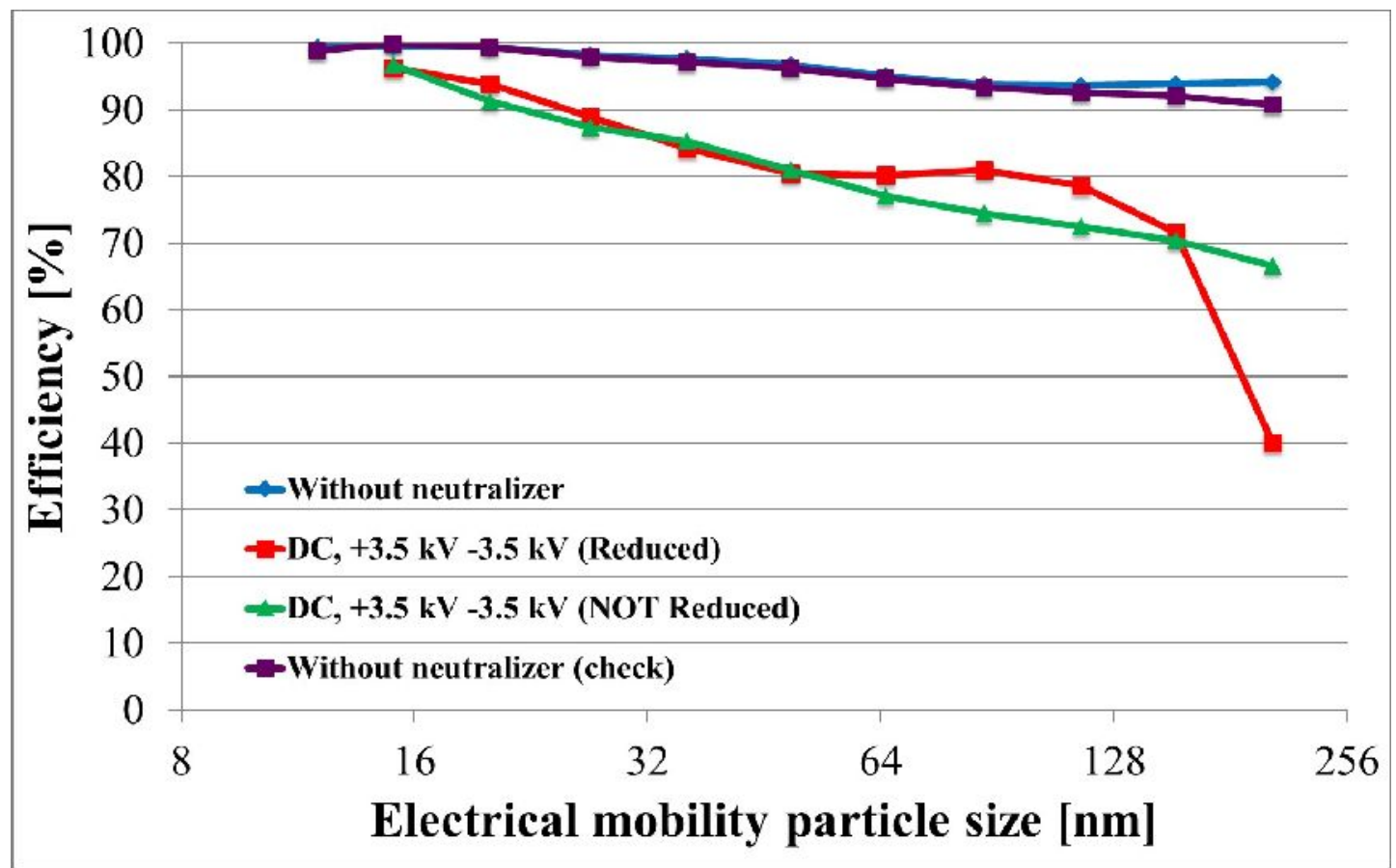

FIGURE 6. Qualification of the neutralization using filter media FA6900NW with reduced particles concentration. 


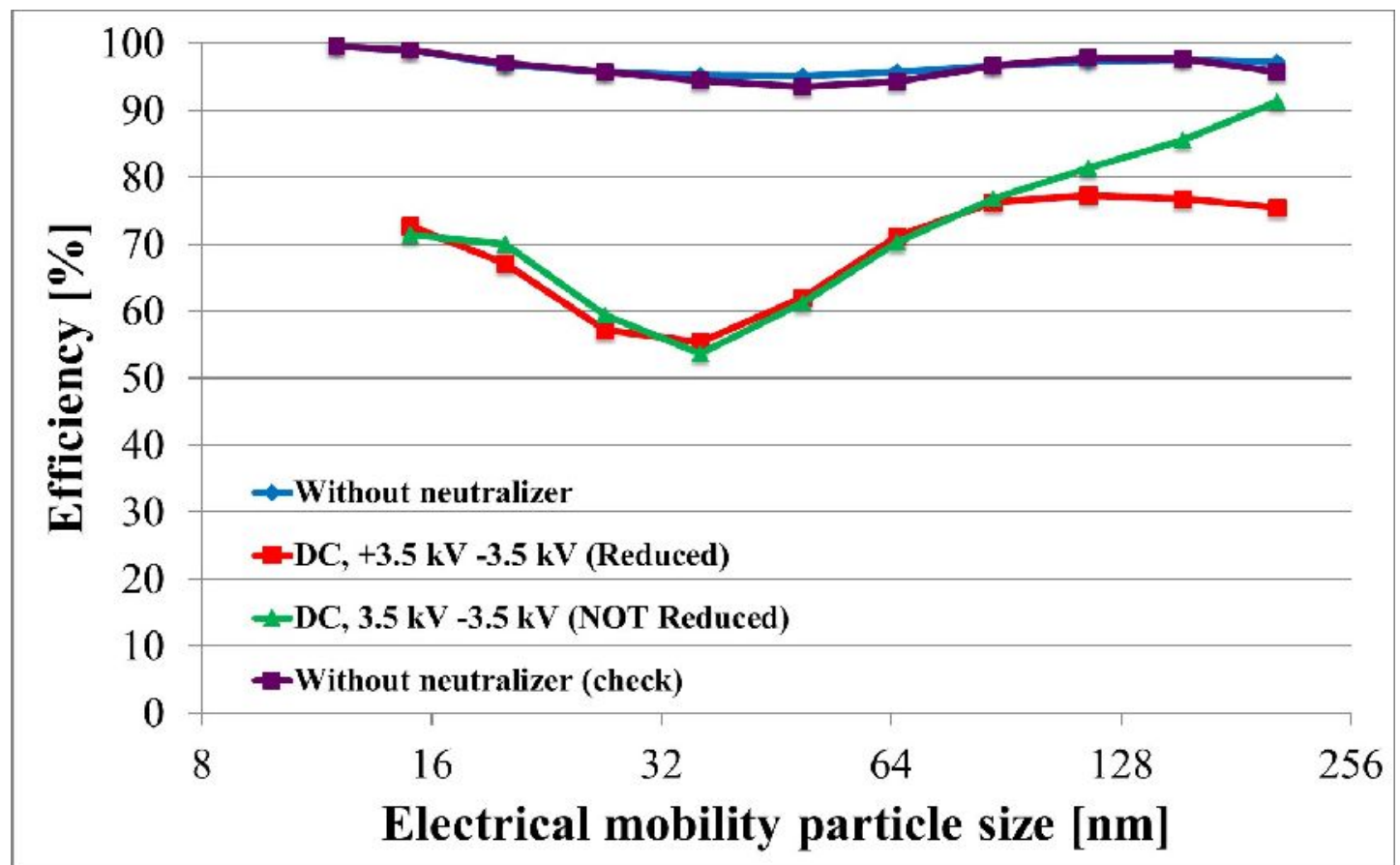

FIGURE 7. Qualification of the neutralization using filter media Technostat with reduced particles concentration.

It is observed in figures 6 and 7 how the neutralizer does not influence the behavior of the two filters over time. Control tests were performed without neutralizing at the beginning and at the end of the test. Therefore, neutralization has no influence on the filtering performance of the two materials.

Comparing the tests performed with the different concentrations, the behavior was slightly different. In fact, the two curves are very similar, until about $75 \mathrm{~nm}$, them above this size they tend to deviate. The explanation may be due to the fact that the particle counter used works in the range of size of 10 to $420 \mathrm{~nm}$, but the accuracy of the results is ensured only for smaller sizes. This was also confirmed by the company that produces the instrument, since the measurement accuracy is much better below $100 \mathrm{~nm}$. Other possible explanations are the fact that the charge level on the filter may change over time and use, which may influence the results, and the fact that the particle parameter, in this case the concentration, may influence the collection mechanisms (WANG ; TRONVILLE, 2014).

After the qualification tests it was concluded that the chosen setting (DC -3.5 $\mathrm{kV}+3.5 \mathrm{kV}$ ) is the best neutralizer setting for that specific test. The use of two filter media with different collection efficiency and different predominant filtering mechanisms helps to have greater reliability in the results as the same conclusion was reached for both filter media.

\section{CONCLUSIONS}

The objective of this study was to qualify a corona discharge aerosol neutralizer and show how this part of the process is very important for aerosol filtration. From the obtained results it was possible to prove that the qualification of an aerosol neutralizer is a fundamental procedure for air filtration experiments. These qualification tests ensured optimum performance of the equipment individually and 
were able to minimize errors and prevent risks that can mask the obtained data.

An important point that was noted is that small variations in the experimental parameters or the test rig led to different results. This also occurred for the aerosol neutralization during air filtration experiments. Qualification cannot guarantee data repeatability unless operating parameters are maintained and the rig test is performed under exactly the same operating conditions.

Thus, aerosol neutralization is necessery in the air filtration process, can affect the efficiency of submicron particle filtration. With qualification, it is possible to determine whether this equipment performs at its best for a radioactive neutralizer or to determine the best working configuration for a Corona discharger neutralizer.

It is worth remembering that aerosol neutralization is only one step in the particle counting process. Therefore, for the data obtained to be more reliable all equipment and processes must undergo some sort of qualification and validation.

\section{ACKNOWLEDGEMENTS}

The authors thank to Chemical Engineering Postgraduate Program of UFSCar and to Energy Department of Politecnico di Torino for the structure provided, to CAPES for funding through process 88881.030417/2013-01 and CNPq for the scholarship.

\section{REFERENCES}

ADACHI, M.; OKUYAMA, K.; KOUSAKA, Y.; KOZURU, H. AND PUI, D. Y. H. Bipolar Diffusion Charging of Aerosol Particles Under High Particle/lon Concentration Ratios. Aerosol Science and Technology. v.11, p.114-156. 1989. Disponível em: https://www.tandfonline.com/doi/pdf/10.1080/02786828908959307 DOI: https://doi.org/10.1080/02786828908959307

ADACHI, M.; PUI, D. Y. H. AND LIU, B. Y. H. Aerosol Charge Neutralization by a Corona lonizer. Aerosol Science and Technology, v.18:1, p.48-58. 1993. Disponível em: https://www.tandfonline.com/doi/pdf/10.1080/02786829308959583 DOI: https://doi.org/10.1080/02786829308959583

ALONSO, M. AND ALGUACIL, F. J. Particle Size Distribution Modification During and After Electrical Charging: Comparison between a Corona lonizer and a Radioactive Neutralizer. Aerosol and Air Quality Research. v.8:4, p.366-380. 2008. Disponível em: http://aerosol.ieexa.cas.cn/aaqrkw/kwlwqj/201207/W020120727557058403811.pdf DOI: 10.4209/aaqr.2008.07.0029

BENNETT, A. Developments in air \& gas filtration technology. Filtration+Separation (September/October). $\quad 2016.30-35 . \quad$ Disponível em: https://www.sciencedirect.com/science/article/pii/S0015188216302105 DOI: https://doi.org/10.1016/S0015-1882(16)30210-5

BULEJKO, P.; KRIŠTOFA, O.; DOHNALB, M.; SVĚRÁK, T. Fine/ultrafine particle air filtration and aerosol loading of hollow-fiber membranes: A comparison of mathematical models for the most penetrating particle size and dimensionless 
permeability with experimental data. Journal of Membrane Science. V.592. 117393. 2019.

GAUDERMAN, W.J.; URMAN, R.; AVOL, E.; BERHANE, K.; MCCONNELL, R.; RAPPAPORT, E.; CHANG, R.; LURMANN, F.; GILLILAND, F. Association of Improved air quality with lung development in children. The New England Journal of Medicine. v.372, p.905-913. 2015. Disponível em: https://www.nejm.org/doi/full/10.1056/NEJMoa1414123 10.1056/NEJMoa1414123

HINDS W.C. Aerosol Technology: Properties, Behavior and Measurement of Airborne Particles. Wiley Interscience. 1999. Disponível em: https://www.wiley.com/en-

br/Aerosol+Technology:+Properties,+Behavior,+and+Measurement+of+Airborne+Par ticles,+2nd+Edition-p-9780471194101

JI, J. H.; BAE, G. N.; HWANG, J. Characteristics of aerosol charge neutralizers for highly charged particles. Aerosol Science. v.35, p.1347-1358. 2004. Disponível em: https://www.sciencedirect.com/science/article/pii/S0021850204000965 DOI: https://doi.org/10.1016/j.jaerosci.2004.04.008

KALLINGER, P.; STEINER, G. AND SZYMANSKI, W. W. Characterization of four different bipolar charging devices for nanoparticle charge conditioning. Journal of Nanoparticle Research. v.14, p.944-951. 2012. Disponível em: https://link.springer.com/article/10.1007\%2Fs11051-012-0944-z DOI: http://dx.doi.org/10.1007/s11051-012-0944-z

LI, S.; GUO, Y.; WILLIAMS, G. Acute impact of hourly ambient air pollution on preterm birth. Environmental Health Perspectives. v.124(10), p.1623-1629. 2016. Disponível em: https://www.ncbi.nlm.nih.gov/pmc/articles/PMC5047774/ DOI: 10.1289/EHP200

MARIAM; JOSHI, M.; KHANDARE, P.; KOLI, A.; KHAN, A.; SAPRA, B.K. Influence of sheath air humidity on measurement of particle size distribution by scanning mobility particle sizer. Journal of Aerosol Science. v.111, p.18-25. 2017. Disponível em: https://www.sciencedirect.com/science/article/pii/S0021850216304396 DOI: https://doi.org/10.1016/j.jaerosci.2017.05.005

NGUYEN, T.K.V., PETTERS, M.D., SUDA, S.R., GUO, H., WEBER, R.J., CARLTON, A.G. Trends in particle-phase liquid water during the Southern Oxidant and Aerosol Study. Atmospheric Chemistry and Physics. v.14 (20), p.1091110930. 2014. Disponível em: https://www.atmos-chem-phys.net/14/10911/2014/acp14-10911-2014.pdf DOI: https://doi.org/10.5194/acp-14-10911-2014

OHMI, T.; SUDOH, S.; MISHIMA, H. Static charge removal with IPA solution. IEEE Transactions on Semiconductor Manufacturing. v.7, p.440-446. 1994. Disponível: 
https://ieeexplore.ieee.org/document/330281 DOI: 10.1109/66.330281

SACHINIDOU, P., BANK, Y.K. AND WANG, J. An integrative model for the filtration efficiencies in realistic tests with consideration of the filtration velocity profile and challenging particle size distribution. Aerosol Science and Technology. v.51, p.178-187. 2016.

em: https://www.tandfonline.com/doi/full/10.1080/02786826.2016.1254720 DOI: 10.1080/02786826.2016.1254720

SACHINIDOU, P.; BAHK, Y.K.; TANG, M.; ZHANG, N.; CHEN, S.; PUI, D.Y.H; LIMA, B.A.; BOSCO, G.; TRONVILLE, P.; MOSIMANN, T.; ERIKSSON, M.; WANG, J. Interlaboratory validation of the method to determine the filtration efficiency for airborne particles in the $3-500 \mathrm{~nm}$ range and results sensitivity analysis. Aerosol and Air Quality Research. v.17, p.2669-2680. 2017. Disponível em: http://www.aaqr.org/files/article/3475/4_AAQR-17-03-WFC12-0104_2669-2680.pdf DOI: 10.4209/aaqr.2017.03.0104

SARANGI, B.; AGGARWAL, S. G.; GUPTA, P. K. A simplified approach to calculate particle growth rate due to self-coagulation, scavenging and condensation using smps measurements during a particle growth event in New Delhi. Aerosol and Air Quality Research. v.15, p.166-179. 2015. Disponível em: http://www.aaqr.org/files/article/374/14_AAQR-13-12-OA-0350_166-179.pdf DOI: 10.4209/aaqr.2013.12.0350

SARANGI, B.; AGGARWAL, S. G.; GUPTA, P. K. Performance check of particle size standards within and after shelf-life using differential mobility analyzer. Journal of Aerosol Science. v.103, p.24-37. 2017. Disponível em: https://www.sciencedirect.com/science/article/pii/S0021850216300751 DOI: https://doi.org/10.1016/j.jaerosci.2016.10.002

STACEY, B. Measurement of ultrafine particles at airports: A review. Atmospheric Environment. v.198, p.463-477. 2019. Disponível em: https://www.sciencedirect.com/science/article/pii/S1352231018307313 DOI: https://doi.org/10.1016/j.atmosenv.2018.10.041

STOMMEL, Y.G. AND RIEBEL, U. A corona-discharge-based aerosol neutralizer designed for use with the SMPS-system. Journal of Electrostatics. v.63, p.917-921. 2005.

Disponível

em: https://www.sciencedirect.com/science/article/pii/S030438860500080X DOI: https://doi.org/10.1016/j.elstat.2005.03.061

TAGHVAEE, S.; MOUSAVI, A.; SOWLAT, M. H.; SIOUTAS, C. Development of a novel aerosol generation system for conducting inhalation exposures to ambient particulate matter (PM). Science of the Total Environment. v.665, p.1035-1045. 2019.

DOI: https://doi.org/10.1016/j.scitotenv.2019.02.214 
TAN, H., CAI, M., FAN, Q., LIU, L., LI, F., CHAN, P.W., DENG, X., WU, D. An analysis of aerosol liquid water content and related impact factors in Pearl River Delta. Science of the Total Environment. v.579, p.1822-1830. 2016. Disponível em: https://www.sciencedirect.com/science/article/pii/S004896971632633X DOI: https://doi.org/10.1016/j.scitotenv.2016.11.167

WAI, W.; TAM, S.; WONG, T.W.; WONG, A.H.S. Association between air pollution and daily mortality and hospital admission due to Ischaemic heart diseases in Hong

Kong. Atmospheric Environment. 2015. Disponível em: https://www.sciencedirect.com/science/article/pii/S1352231015303137 DOI: https://doi.org/10.1016/j.atmosenv.2015.08.068

WANG, J. AND TRONVILLE, P. Toward standardized test methods to determine the effectiveness of filtration media against airborne nanoparticles. Journal of Nanoparticle Research. v.16, p.2417. 2014. Disponível em: https://link.springer.com/article/10.1007/s11051-014-2417-z DOI: 10.1007/s11051014-2417-z

WANG, Y.; FANG, J.; ATTOUI, M.; CHADHA, T.S.; WANG, W-N.; BISWAS, P. Application of Half Mini DMA for sub $2 \mathrm{~nm}$ particle size distribution measurement in an electrospray and a flame aerosol reactor. Journal of Aerosol Science. v.71, p.52-64. $2014 . \quad$ Disponível em: https://www.sciencedirect.com/science/article/pii/S0021850214000202 DOI: https://doi.org/10.1016/j.jaerosci.2014.01.007

WHO (World Health Organization). Ambient (Outdoor) Air Quality and Health. 2014. Disponível em: https://www.who.int/news-room/fact-sheets/detail/ambient-(outdoor)air-quality-and-health

WHO (World Health Organization). Exposure to Ambient Air Pollution From Particulate Matter for 2016. 2018. Disponível em: https://www.who.int/airpollution/data/AAP_exposure_Apr2018_final.pdf?ua=1

XIAO, H.; SONG, Y.; CHEN, G. Correlation between charge decay and solvent effect for melt-blown polypropylene electret filter fabrics. Journal of Electrostatics. v.72, p.311-314. $2014 . \quad$ Disponível em: https://www.sciencedirect.com/science/article/pii/S0304388614000448 DOI: https://doi.org/10.1016/j.elstat.2014.05.006

ZHENG, C.; ZHANG, X.; YANG, Z.; LIANG, C.; GUO, Y.; WANG, Y.; GAO, X. Numerical simulation of corona discharge and particle transport behavior with the particle space charge effect. Journal of Aerosol Science. v.118, p.22-33. 2018. Disponível em: https://www.sciencedirect.com/science/article/pii/S0021850217304238 DOI: https://doi.org/10.1016/j.jaerosci.2018.01.008 